\title{
Design and construction of a 3D force plate prototype for developing an instrumented swimming start block
}

\author{
Luis Mourão ${ }^{1,2}$, Karla de Jesus ${ }^{2}$, Nuno Viriato ${ }^{3}$, Ricardo J. Fernandes ${ }^{2,4}$, J oão Paulo Vilas-Boas ${ }^{2,4}$, \\ Mário A. P. Vaz ${ }^{3,4}$ \\ 1. Superior School of Industrial Studies and Management, Porto Polytechnic Institute, Vila do Conde, Portugal. 2. Centre \\ of Research, Education, Innovation and Intervention in Sport, Faculty of Sport, University of Porto, Porto, Portugal. 3. \\ Institute of Mechanical Engineering and Industrial Management, Faculty of Engineering, University of Porto, Porto, \\ Portugal. 4. Porto Biomechanics Laboratory, University of Porto, Porto, Portugal. \\ Correspondence: Karla de Jesus. Address: Centre of Research, Education, Innovation and Intervention in Sport, Faculty \\ of Sport, University of Porto, Porto, Portugal. Email: karla_de_jesus@yahoo.com.br
}

Received: December 13, 2015

DOI : $10.5430 /$ jbei.v2n2p99
Accepted: January 17, $2016 \quad$ Online Published: February 28, 2016

URL: http://dx.doi.org/10.5430/jbei.v2n2p99

\section{Abstract}

Force plates have been used in human movement analysis to measure ground reaction forces, centre of pressure (COP) and derived kinetic quantities. In competitive swimming external tridimensional (3D) forces assessment is crucial to improve starting technique performance. This work aimed to describe the design and construction of a 3D force plate prototype, which might be a modular sensor of an instrumented swimming starting block. For this purpose four steps were followed: 1) numerical determination of sensor conspicuous spatial positioning; 2) development of a first test device and respective calibration procedures; 3) final prototype (3D force plate) development and implementation; and 4) development and programming of a high speed multiple data acquisition system. Vertical force $(<140 \mathrm{~N} \pm 5 \%)$ and COP real time determination ( $\pm 3 \%$ to centre distance uncertainty) are compliant with the literature data and horizontal force is assessed based on COP displacement time derivatives. The software for data acquisition and interpretation was developed, leading to calibration procedure that provides a set of gains for sequential balance protocol and final transfer matrix. Although the final prototype implementation was the main concern of the current study, its development also has proven to be an important milestone for a dynamometric swimming start block advance.

\section{Key words}

Instrumentation, Kinetics, Ground reaction forces, Swimming

\section{I ntroduction}

Human locomotion is intrinsically connected to developed ground reaction forces ${ }^{[1]}$. In swimming individual and relay starts, this contact is restricted to the block phase ${ }^{[2]}$, with the corresponding external forces being analysed since the Elliot and Sinclair's pioneer instrumented block ${ }^{[3]}$. Currently, coaching and commercial instrumentation are still lacking some of final solutions and important features ${ }^{[4]}$ inspiring new biomechanical research directions. For instance, it is well known that the external kinetic analysis is crucial to determine the parameters that influence the different swimming start techniques ${ }^{[2,5]}$ and that previous ventral start related studies have recommended that elite swimmers should work towards producing high levels of peak force resulting in better start performance ${ }^{[2]}$. 
For start optimisation, if a limb is in contact to a force platform, the respective 3D force and momentum should be measured to maximise training efficiency ${ }^{[6]}$. Each of the two vectors are tridimensional (3D) and have to be decomposed in three Cartesian components $\vec{F}=\left(F_{x}, F_{y}, F_{z}\right)$ and $\vec{M}=\left(M_{x}, M_{y}, M_{z}\right)$ with $\mathrm{x}$, y and $\mathrm{z}$ framed according to the International Society of Biomechanics ${ }^{[7]}$. The $\vec{F}$ vector components are due to swimmers' weight and dynamic effects ${ }^{[5]}$ and the respective reaction is a symmetrical propulsive 3D quantity (according to Newton's action-reaction third law). The $\vec{M}$ measurement is used for assessing contact position - the centre of pressure (COP). Hence, it is possible to obtain the 3D force time history (available after calibration and zero adjustment operations) and the COP migration, requiring the topology of the contact surface to correct its assessment.

Ground reaction force effect in the swimmers' starting movements can be computed if considering it applied to a body with known centre of mass (CM), weight and inertia matrix. Such force and moment of force can be appropriately time integrated to provide impulse and velocity (if the swimmers' mass is known) or displacement (by double time integration). In addition, the moment of force measured at each contact point allows locating the COP of each limb, which can also evidence postural effects ${ }^{[5,8]}$. To perform this detailed measurement, a tailored platform set is needed, which should be inserted in a new structure suitable for swimming start performance assessment. It should be designed and instrumented to obtain a bundle of signals, giving full information concerning the exerted force (including its COP). After a proper calibration ${ }^{[1,8]}$, this device could also be used in day-to-day biomechanical evaluation procedures as a force platform for static balance ${ }^{[8,9]}$ or even for gait ${ }^{[10]}$ and jump analysis ${ }^{[6]}$.

Force platforms are devices used for force evaluation through performed measurements on structures in contact to limbs ${ }^{[11]}$. These measurements can be carried out with strain gauges ${ }^{[12]}$, piezoelectric devices ${ }^{[2]}$ or with fibre optic sensors ${ }^{[13]}$. Strain gauges present relevant advantages over piezoelectric sensors, such as better stability for long-term measurements providing absolute measurements instead of relative ones ${ }^{[13]}$. Piezoelectric sensors require a specific signal-conditioning device known as a charge amplifier ${ }^{[13]}$. The strain gauge is bonded on the surface of a mechanical structure whose geometry definition (among several sensor topologies that have been used ${ }^{[14-16]}$ ) impacts in the force plate project and the final selected topology should be based on simplicity and robustness criteria ${ }^{[16]}$.

An instrumented swimming start block capable to assess independently swimmers' right and left upper and lower limb forces produced in all existent start techniques and respective variants would be a very relevant tool for training purpose. Current devices for force measurement applications in swimming starts (and turns) are, though, unable to allow some signal separation and avoid crosstalk ( $c f .{ }^{[4]}$ for a review on the topic). For example, Slawson et al. ${ }^{[2]}$ used two sagittal aligned platforms dedicated to track start characterisation, not allowing laterality contribution apartness in the grab start technique. Cavanagh et al. ${ }^{[15]}$ and Galbraith et al. ${ }^{[17]}$ assessed force produced by the hands simultaneously in mixed kinetics, with splitting the individual hands force contribution apart being impossible, once again. Thus, the high replication number forecast to cover all above mentioned possibilities imply a careful load cell choice as cost could rise excessively. The current work aimed to design and construct a low cost 3D force plate prototype composed by a hollow pipe topology and simple anchorage. This force plate would be the core concept of an extended dynamometric device, built by its simple reproduction in proper location. Using such arrangement it would be possible to map completely the limbs reaction force produced in swimming starts, allowing more objective and reliable coaching feedback.

\section{Materials and methods}

\subsection{Definition of measurement premises and calibration}

The force plates design has initiated using CAD (3D CAD, DS Solidworks, Dassault Systèmes S.A., France) to define prototype geometry. Following previous platform designs ${ }^{[16,18]}$, an aluminium cylindrical shell (pipe) load cell, complying with known mechanical properties (e.g. Young modulus and Poisson ratio consistent with the project requirements and the appropriated strain gauges selected) was chosen (see Figure 1, A panel) in accordance to the necessary stiffness and estimated load amplitude. Although modelling the conspicuous positioning of the sensors was 
defined as thoroughly as possible, some constraints had to be addressed, particularly the establishment of a preferential vertical force direction (using a 1,000 N vertical force load) and the COP locus of the respective force vector (defined as the top plane and materialised on the top cap surface; see Figure 1, B panel). Due to symmetry, only a squared quarter of the available area was used in the simulation and the test device resonance frequency and the strain-simulated signals (see Figure 1, C panel) were obtained by numerical methods using ANSYS 14.0 software (ANSYS ${ }^{\circledR}$ Workbench $^{\mathrm{TM}} 2.0$ Dassault Systems, France).

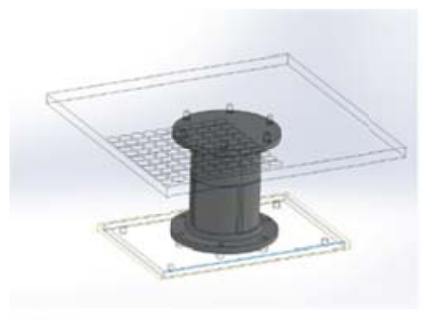

A)

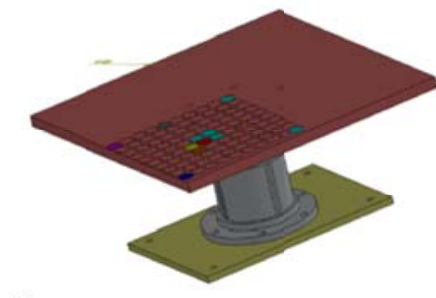

B)

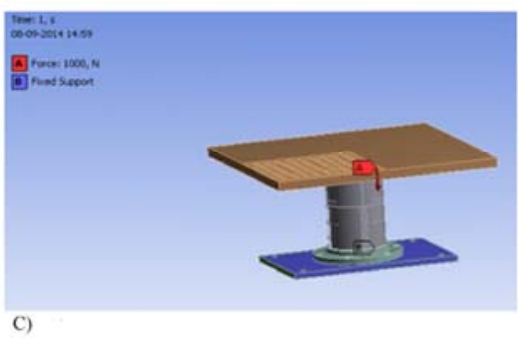

Figure 1. Load cell design approach to simulated operation. A) Perspective of load cell main component. B) Target areas for force application. C) Exemplar border vertical force of $1000 \mathrm{~N}$ for simulation.

Calibration algorithms were developed to transfer functions assessment, focused on matrices applied to all signals obtained from sensors, to provide object dynamical force-moment behaviour. The main algorithm was based in a signal normalisation obtained with a central positioned vertical force. The linearization of the main transfer function of each sensor for the exactly same strain signal results from symmetry. The main transfer function for vertical force measurement is given by the following equation:

$$
F_{z}=\frac{1}{4}\left(A_{1} \varepsilon_{1}+A_{2} \varepsilon_{2}+A_{3} \varepsilon_{3}+A_{4} \varepsilon_{4}\right)
$$

where $A_{1}, A_{2}, A_{3}, A_{4}$ are the gain-calibration parameters to provide strain to force ratio $(\mathrm{N} / \mu \varepsilon)$, the paired $\varepsilon_{1}, \varepsilon_{2}(\mu \varepsilon)$ are the strain outcome and sensor positioning defining the $\mathrm{x}$ axis or lateral direction (respectively), the $\varepsilon_{3}, \varepsilon_{4}$ is the pair sensor positioning that defines $y$ axis or horizontal direction and $F_{z}$ is the vertical reaction to the vertical force applied. If a mismatch of the cover centre is produced, modifying the COP of the resulting applied force, the imbalance obtained between opposite sensors reveals its coordinates according to the following pair of equations:

$$
\left\{\begin{array}{l}
x_{C O P}=\frac{h \cdot F_{x}-M_{y}}{F_{z}} \\
y_{C O P}=\frac{h \cdot F_{y}+M_{x}}{F_{z}}
\end{array}\right.
$$

where $M_{x}$ and $M_{y}(\mathrm{~N} \cdot \mathrm{m})$ are $\mathrm{x}$ and $\mathrm{y}$ torque components, $F_{x}$ and $F_{y}(\mathrm{~N})$ are $\mathrm{x}$ and $\mathrm{y}$ force components, $\mathrm{h}(\mathrm{m})$ is the height of the top platform cover plane to strain-gauge sensor vertical distance and $x_{C O P}(m)$ and $y_{C O P}(m)$ are COP coordinates in a Published by Sciedu Press 
frame on the cover plane (centred at mid distance of the four sensors) with $\mathrm{x}$ and $\mathrm{y}$ axis previously defined. Moment assessment and COP determination can be obtained, in practice, according to the following pair of equations (variants of Equations 2):

$$
\left\{\begin{array}{l}
x_{C O P}=\frac{I E}{W \emptyset}\left(A_{1} \varepsilon_{1}-A_{2} \varepsilon_{2}\right) \\
y_{C O P}=\frac{I E}{W \varnothing}\left(A_{3} \varepsilon_{3}-A_{4} \varepsilon_{4}\right)
\end{array}\right.
$$

Where $I=\frac{\pi}{64}\left(\emptyset_{\text {ext }}^{4}-\emptyset_{\text {int }}^{4}\right)\left(m^{4}\right)$ is the axial inertia momenta around the centre of the load cell tube (with $\emptyset_{\text {ext }}(\mathrm{m})$ as the external diameter and $\emptyset_{\text {int }}(\mathrm{m})$ as the internal diameter), $\mathrm{E}=7.1 \times 10^{10} \mathrm{~Pa}$ is the pipe aluminium Young modulus, $\mathrm{W}(\mathrm{N})$ is the weight applied (or $F_{z}$ ) and $\varnothing(\mathrm{m})$ is the tube diameter (the external diameter was assumed due to the small thickness of the tube wall).

At last, with the position of COP, it is possible to assess force $F_{x}$ and $F_{y}(\mathrm{~N})$ components, as the following equations state.

$$
\left\{\begin{array}{l}
F_{x}=m \frac{d^{2}\left(x_{C O P}\right)}{d t^{2}} \\
F_{y}=m \frac{d^{2}\left(y_{C O P}\right)}{d t^{2}}
\end{array}\right.
$$

Where $m(\mathrm{~kg})$ is the mass of the body and $\frac{d^{2}\left(x_{C O P}\right)}{d t^{2}}, \frac{d^{2}\left(y_{C O P}\right)}{d t^{2}}\left(m \cdot s^{-2}\right)$ are the COP position second time derivative or acceleration on cover plane components. However, these values are limited to contact area (a $1 \mathrm{~kg}$ pendulum with $3 \mathrm{~kg}$ base has been used for test) and are also dependent on the sampling rate, demanding a low noise data acquisition system for reliable values if numerical differentiation is used.

\subsection{Development of a first test device and respective calibration procedures}

Following the earlier mentioned simulations, the test device was designed, assembled and instrumented with four strain gauges of $120 \Omega$ 1-LY41-6/120, Self-Temperature-Compensation Gages (HBM, Germany). The strain gauges were configured as four $1 / 4$ Wheatstone bridge circuit for axial strain measurements, whose bridge topology allows the measurement of the independent strain in each sensor loci due to different force application points or COP locus assessment. No temperature compensation was applied, as manufacturer claims that the strain gauges were quite insensitive to $1.8 \mu \mathrm{m} / \mathrm{m} /{ }^{\circ} \mathrm{C}$ or $\mu \varepsilon /{ }^{\circ} \mathrm{C}$ in a temperature range of $10^{\circ} \mathrm{C}$ to $80^{\circ} \mathrm{C}$.
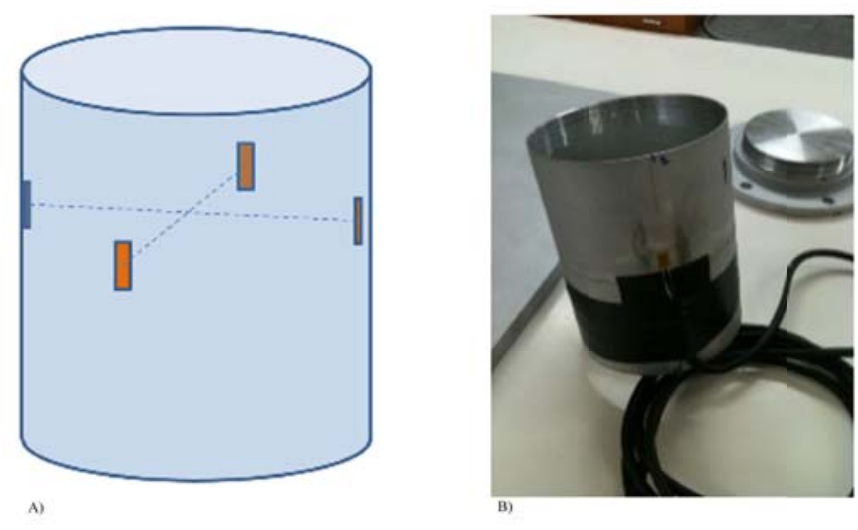

Figure 2. Load Cell implementation. A) Strain-gauge loci. B) Strain gauge bonded in the load cell. 
Four strain gauges were bonded to the cylindrical tube (see Figure 2, A panel) where it is exhibited the strain-gauge loci in the middle of the outside tube generatrix and respective final implementation (see Figure 2, B panel). For strain data acquisition it was used was a NI SCXI-1001 Chassis with NI SCXI-1520 8-Channel Universal Strain Gauge Input Module connected to NI SCXI-1314 Front-Mounting Terminal Block, all devices from National Instruments Corporation (NI Corporation, USA).

The force calibration procedure involved a set of eight cylindrical lead masses of $\sim 10 \mathrm{~kg}$ (each mass had $245 \mathrm{~mm}$ Radius $\times$ $15 \mathrm{~mm}$ height). A $0.2 \mathrm{~kg}$ stainless steel cylindrical pin support, with $20 \mathrm{~mm}$ diameter $\times 40 \mathrm{~mm}$ height (representing a contact area less than $5 \%$ of the platform cover area) was attached to a convenient weight insertion cavity. It was intended to apply forces perpendicular to the platform cover, which was horizontally placed. To calibrate vertical forces, the pin was centred in the middle of the platform cover and increasing values of weight were applied. The linearization of such data samples led to the transfer function of the vertical force that, for centred vertical force measurement, is given by Equation 3, providing solutions for the linear regressions in the following equations:

$$
A_{1} \varepsilon_{1}=A_{2} \varepsilon_{2}=A_{3} \varepsilon_{3}=A_{4} \varepsilon_{4}
$$

The calibration set-up for vertical central force and moment of force determinations is depicted in Figure 3 (A panel). To perform the moment of force calibration the weight set was positioned decentred in eight equal displacements along each bisector line of the platform square cover borderlines. A small lifting bridge was constructed for load positioning, which gave rise to the same vertical forces but different moments. Hence, nine points of output imbalance signals occurred between pairs of opposite strain gauges, particularly in opposite to the centre and in the line of load displacement (see Figure 3, B panel). This procedure was repeated throughout the other perpendicular direction and data collected were linearized. Data from the 18 load positions was used to obtain COP coordinates from the imbalance values.
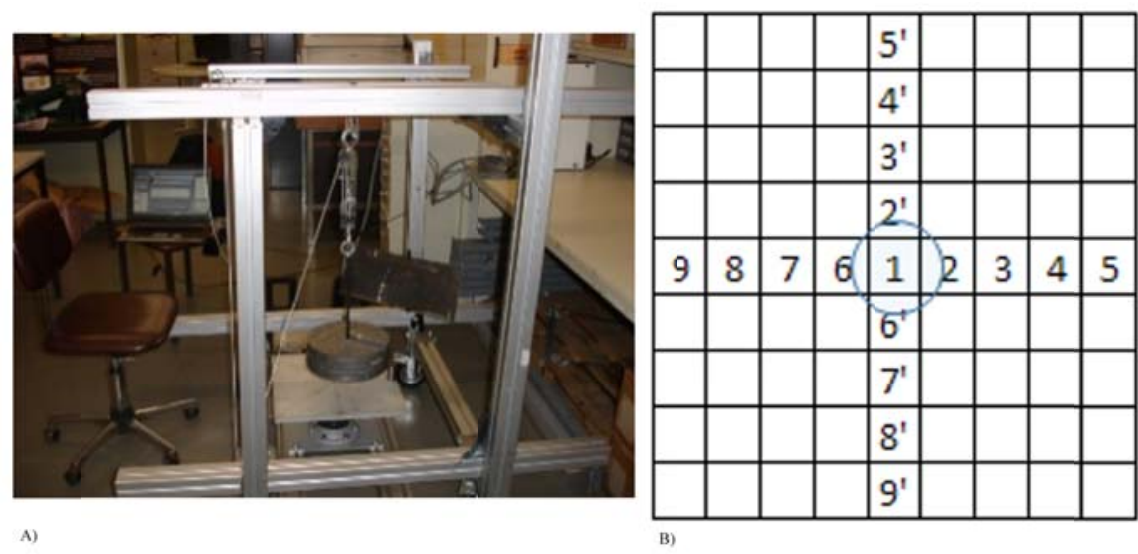

Figure 3. Calibration set-up. A) Set-up for lifting and positioning of force application points. B) Circular area and squared ordinals represents the centred force locus and the COP displacement scheme, respectively.

\subsection{Development and implementation of the final prototype}

Following test device assembly, the final prototype was instrumented, bonding four strain gauges of 350 ohms (SGT-1/ 350-TY11, Self-Temperature-Compensation Gages, HBM, Germany) in a four $1 \frac{1}{4}$ Wheatstone bridge topology circuit for strain measurements. Differently from the previous test device, it was selected a category of strain gauges with greater resistance, reducing the power dissipation since the pipe was $90 \%$ thinner. Similarly to the preceding test device, no temperature compensation was applied and the strain sensitivity was similar.

The four strain gauges were bonded axially to the tube selected for the final prototype. This tube is a thin walled cylindrical shell $0.1 \mathrm{~mm}$ thickness, made by aluminium metal (see Figure 4, A panel) and was an adapted regular beverage can, sealed 
for stability purposes. The same topology, electrical and position constraints of the first device test (see Figure 2, A panel) were applied for force and momentum determination.
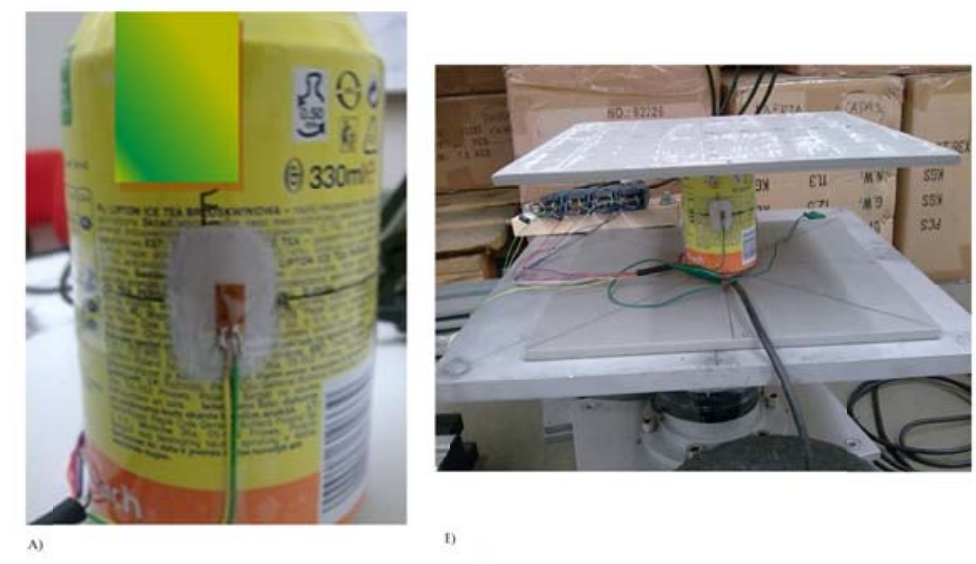

Figure 4. Strain gauges positioning and platform assembly. A) Sensor element of force plate. B) Full structure.

Measuring data were collected with a suitable four channel NI 9237 acquisition board, which was connected to NI USB 9162 module (both from National Instruments Corporation, USA). Both devices ensured simultaneous acquisition data in up to four strain data channels (2,000 sample/s sample rate) and matched the measurement requirements. The final bonded sensors loci and apparatus are depicted in Figure $4 \mathrm{~A}$ and B panels (respectively). Calibration procedure was reproduced following the same procedure of the first test device case (see Figure 3, B panel), but the weight applied was about $10 \%$ lower $(<140 \mathrm{~N}$ range) and the lift bridge was discarded.

\subsection{Development and programming of high speed multiple data acquisition system}

The implemented algorithms have included mainly linear regressions and the outcomes were the resulting individual strain gauge gains $\left(A_{1}, A_{2}, A_{3}, A_{4}\right)$. Total addictive contribution of each individual strain gauge signal gives the equivalent central force to be measured, as in Equation (3). Moment of force linearization was applied and the transfer function was implemented following the Equations (4). The algorithm of measurement of force-torque was implemented using suitable dedicated LabVIEW ${ }^{\circledR}$ (National Instruments Corporation, USA) routine for data storage and presentation. A routine for COP locus assessment and parallel to plane force components $F_{x}$ and $F_{y}$ estimation was included.

Figure 5. Strain pattern in a border weight positioning of $1000 \mathrm{~N}$

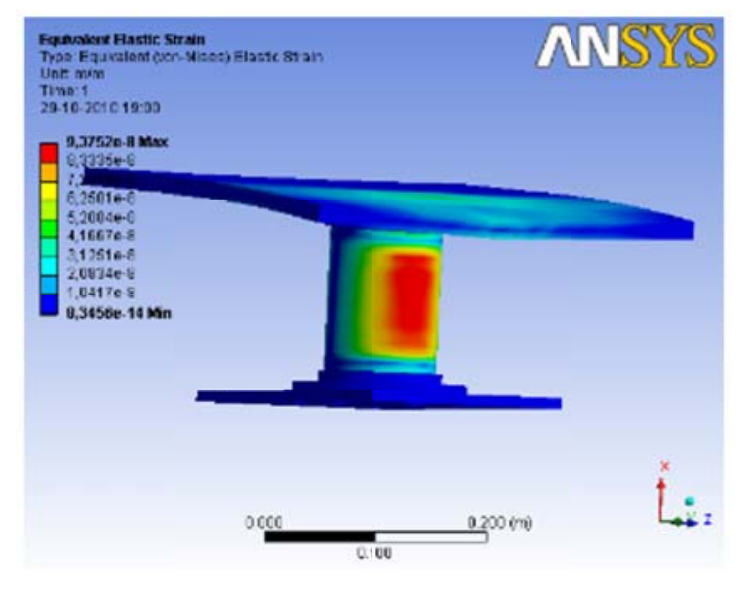




\section{Results}

Both in the first test device and in the final prototype, the evidence of a large area where strain is well defined and maximal values are reached, exhibits the place where strain-gauge should be bonded (see Figure 5). High value resonance frequency modes were achieved (above $200 \mathrm{~Hz}$ ) in both solutions.

Figure 6. Calibration data in normalized strain produced in each positioning for a weight of $42 \mathrm{~N}$

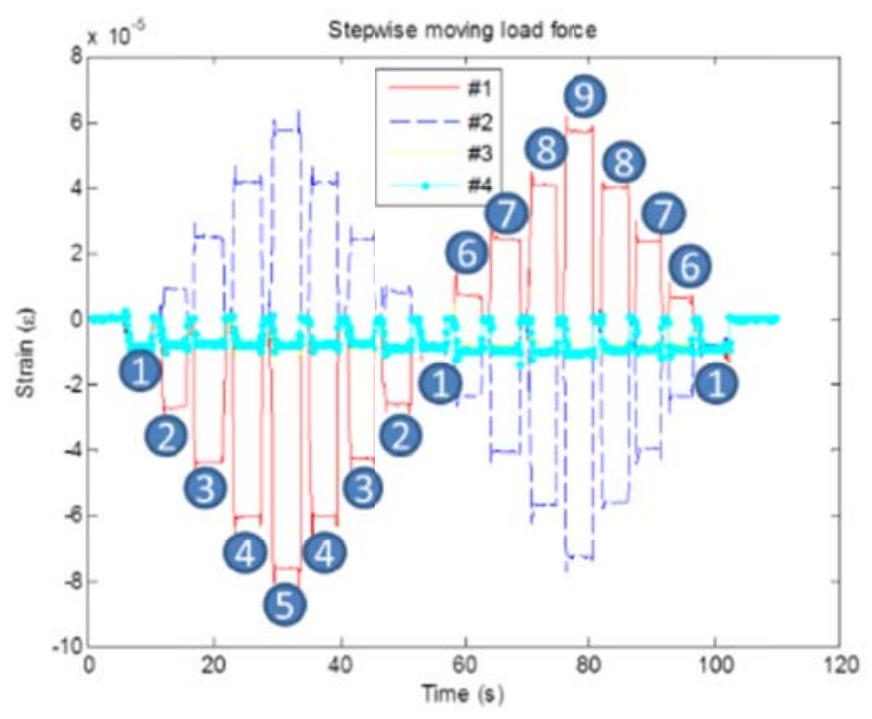

Figure 6 represents the double linearization in force-momentum (in normalised strain measures) while the weight COP is positioned in each of the points depicted in Figure 3 (B panel) applied in the final prototype platform cover. The constant values of the vertical force (in cyan) can be seen in this figure, while regular displacements provide also regular linear increase/decrease of the strain signal combined. The adding of the four calibrated and normalised signals provides the vertical force value and the opposite sensor signal subtraction leads to the on cover plate COP displacement measurement.

Figure 7. LabVIEW $^{\circledR}$ interface and set-up for straightforward results presentation with a pendulum dynamic load

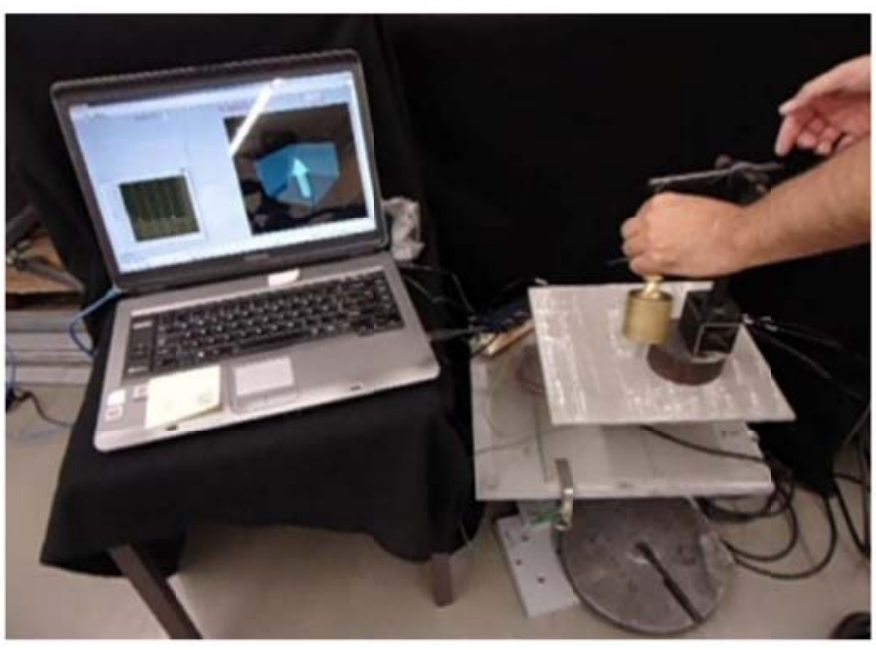

Values of the gains for the developed final prototype ranged between $1.365085 \times 10^{6} \mathrm{~N} / \varepsilon$ and $1.691198 \times 10^{6} \mathrm{~N} / \varepsilon$ for the applied central force, providing an overall uncertainty in the vertical force of about $0.5 \mathrm{~N}$. An upgrade in the software has included numerical differentiation tools that, applied to COP positioning, led to acceleration tangential to plane of platform body with components $a_{x}$ and $a_{y}$. Tangential to force plate cover plane, $F_{x}$ and $F_{y}$ components (see Figure 7 ) are derived from weight and those acceleration components allowing to finally assessing the $3 \mathrm{D}$ force vector. 


\section{Discussions}

Due to present Fédération Internationale de Natation (FINA) starting block facility rule modifications, some researchers have invested in new technologies to measure the external forces applied to the swimming starting block during different starting techniques ${ }^{[2,19,20]}$. In addition, researchers have also evolved their study purposes to separate the effective swimmers' forces from the inertial effects ${ }^{[5]}$, highlighting the crucial role of taking specific and accurate measurements by instrumented starting blocks. The current work aimed to describe the design and construction of a low-cost force platform final prototype, as precursor of a swimming suitable dynamometric central for different start techniques evaluation. The implementation of such platform displayed low vertical force range $(<140 \mathrm{~N})$, high sensitiveness $(\sim 0.5 \mathrm{~N}), 3 \mathrm{D}$ extrapolation and short implementation budget suitable for a modular solution involving several force platforms.

Platform design followed the cylindrical geometry used by Bracci et al. ${ }^{[16]}$ with Esser et al. ${ }^{[18]}$ showing how a very simple topology would be suitable for 3D measurement purposes. Furthermore, such simple geometry proposal is characterised by a shorter budget compared with the commercial devices ${ }^{[19]}$ that provide direct COP assessment together with parallel to cover force measurements (i.e. not in function of COP displacement). The present topology determines the acceptance of measurements based on extrapolations, turning COP position assessment with an uncertainty proportional to centre distance $(\sim 3 \%)$ compared to more elaborated topologies. This uncertainty growth and the obtained distribution exhibit a minimum value in the centre of the platform cover, in agreement with Collins et al. ${ }^{[11]}$. Such difficulty can be overcome by the use of redundancy, reproducing the 3D load cell and locating four of them in the corners ${ }^{[21]}$ or by changing the topology of the load cell ${ }^{[10]}$. The error has been compatible with the topology proposed before ${ }^{[10]}$, while the resonance frequency of the first test device has been found three times greater. However, the force range of the current final prototype is lower than Roesler et al. ${ }^{[10]}$, as the thin pipe wall limits the applied load.

Accurate measurements of ground reaction forces from force plates are important in many areas of biomechanical research ${ }^{[5,8,9]}$. In the current study, force platform design and linearization algorithms have shown to be suitable to force and moment of force assessment (see Figure 6). In fact, the present 3D force plate prototype displayed a very regular and bilinear behaviour to both vertical force and moment of applied force, as presented before ${ }^{[11]}$. In opposition to this study that measured directly uniaxial forces although decentred, the referred authors ${ }^{[11]}$ used calibration procedures that led to COP definition with smaller uncertainty while the current force plate ranks higher uncertainty due to its extrapolation measurement nature. In competitive swimming, moments of force have not been frequently assessed in different start techniques but it is intrinsically connected to COP assessment leading to postural effects that intervene in swimming start performance ${ }^{[5]}$.

Notwithstanding the relevance of present data, some study's limitations should be considered. For strain measurement using strain gauge connected in Wheatstone full bridge arrangement, at least four wires are needed (two for excitation and two for measurement), which is twice the required for piezoelectric sensors. With a $1 / 4$ Wheatstone bridge it is necessary two or three wires (in this case it is possible to assess wire resistance), but the strain signal reduces to a quarter of the full bridge measured. However, the strain gauge sensor represents a highly tested, mature and overspread technology, offering good sensitivity, precise measurements and competitive price ${ }^{[13,14]}$. In addition, noise patterns and high sensitivity to moment of force in large COP displacements suggest the use of more than one load cell tube ${ }^{[8,21]}$, as this is due to the central extrapolation nature of the measurement accomplished with this type of single load cell. With four platform cap cover corner positioned load cells, central COP would be determined with much less uncertainty, as previously mentioned ${ }^{[22]}$. Such new topology, although more expensive, would forecast a minimum centred to cover COP determination uncertainty. However, the first topology cost is incomparably low budget (i.e. $\sim 50 €$ ) if not considering data acquisition system, which could be shrunk with some electronics and microcontroller excitation/data acquisition board. Another geometrical sensor loci apparatus possibility would be to apply Roesler et al. ${ }^{[10]}$ topology, which is uncertainty compatible with Cunningham and Brown ${ }^{[22]}$. 
Despite the above mentioned advantages of the final prototype, which is suitable for force and moment of force measurements, it is recognised that in different start techniques swimmers contact with soil limb postures and loci are variable, weakening the information of a single platform. As swimmers' limbs generate propulsive force, it is required an integer minimum number of platforms for physical conditions general mapping. In addition, the environment of the swimming pool demands waterproof sensors (as the bonding process is hygroscopic and may be damaged). Finally it is expectable to have a regular instrumented block complying with FINA's FR 2.7 and 2.10, rules designing the loci and anchorage of the necessary set of platforms. Such dynamometric central would be available simultaneously for scientific investigation and for coaching purposes, overcoming the limitations depicted in the commercial instrumented starting blocks available ${ }^{[2]}$. According to Walsh et al. ${ }^{[6]}$, one limitation for the use of force plate in training is that they are typically heavy, enhancing the wall mount of the set of platforms and their mechanical fixation importance, which, in turn, should prevent any crosstalk measurement between platforms (as their sensitivity is high). Future studies should take into account of such feature and try to mitigate its effect.

\section{Conclusions}

A device which can be considered the precursor of the next homemade load cell generation has been developed for swimming start performance evaluations, accomplishing the main purpose of vertical force and COP locus determination. It has also measured the horizontal force, providing that its assessment could be calculated by COP displacement, albeit the results assessed have proven to be more uncertain the more off-centre COP of force applied. The main influence has arisen from the central extrapolation nature of the load cell or final prototype, but a low-cost force plate design could be the core of a more vast assembly, reproducing the final prototype a certain amount of times and in combination of other requirements (mechanical, biomechanical and electronics). This device, as a stand-alone solution, could be used to perform measurements in didactical situations, if the precision requirements could be relaxed. Further studies, following final prototype development branch and, in parallel, the biomechanics boundary conditions involved in the swimming starts, should be carried out to develop a general-purpose instrumented swimming start block.

\section{Acknowledgments}

This work was supported by the CAPES Foundation under doctoral grant (BEX 0761/12-5/2012-2015) and FCT Foundation under grant (EXPL/DTP-DES/2481/2013- FCOMP-01-0124-FEDER-041981).

\section{Conflict of interests}

The authors declare that there is no conflict of interest regarding the publication of this paper.

\section{References}

[1] Cappello A, Bagalà F, Cedraro A, et al. Non-linear re-calibration of force platforms. Gait Posture. 2011; 33(4): 724-6. PMid:21392999. http://dx.doi.org/10.1016/j.gaitpost.2011.02.008

[2] Slawson S, Conway P, Cossor J, et al. The categorisation of swimming start performance with reference to force generation on the main block and footrest components of the Omega OSB11 start blocks. J Sports Sci. 2013; 31(5): 468-78. PMid:23131017. http://dx.doi.org/10.1080/02640414.2012.736631

[3] Elliott GM, Sinclair H. The influence of block angle on swimming sprint starts. Proceedings of the I Symposium on Biomechanics and Medicine in Swimming: Universitaire de Bruxelles. 1971: 183-9p.

[4] Mourão L, de Jesus K, de Jesus K, et al. External kinetics in individual and relay swimming starts: a review. Proceedings of the XIIth Symposium on Biomechanics and Medicine in Swimming: Australian Institute of Sport, Canberra. 2014: 179-84p.

[5] Mourão L, de Jesus K, Roesler H, et al. Effective swimmer's action during the grab start technique. PLoS One. 2015; 15: e0123001. PMid:25978370. http://dx.doi.org/10.1371/journal.pone.0123001

[6] Walsh MS, Ford KR, Bangen KJ, et al. The validation of a portable force plate for measuring force-time data during jumping and landing tasks. J Strength Cond Res. 2006; 20(4): 730-4. PMid:17194240. 
[7] Wu G, Siegler S, Allard P, et al. ISB recommendation on definitions of joint coordinate system of various joints for the reporting of human joint motion--part I: ankle, hip, and spine. International Society of Biomechanics. J Biomech. 2002; 35(4): 543-8. http://dx.doi.org/10.1016/S0021-9290(01)00222-6

[8] Browne J, O’Hare N. A quality control procedure for force platforms. Physiol Meas. 2000; 21(4): 515-24. PMid:11110249. http://dx.doi.org/10.1088/0967-3334/21/4/308

[9] Walicka-Cupryś K, Przygoda Ł, Czenczek E, et al. Balance assessment in hearing-impaired children. Res Dev Disabil. 2014: 35(11): 2728-34. PMid:25077831. http://dx.doi.org/10.1016/j.ridd.2014.07.008

[10] Roesler H, Haupenthal A, Schutz GR, et al. Dynamometric analysis of the maximum force applied in aquatic human gait at $1.3 \mathrm{~m}$ of immersion. Gait Posture. 2006; 24(4): 412-7. PMid:16716592. http://dx.doi.org/10.1016/j.gaitpost.2005.09.014

[11] Collins SH, Adamczyk PG, Ferris DP, et al. A simple method for calibrating force plates and force treadmills using an instrumented pole. Gait Posture. 2009; 29(1): 59-64. PMid:18755590. http://dx.doi.org/10.1016/j.gaitpost.2008.06.010

[12] Tsunakawa T, Nakashima M, Takagi H. Use of pressure distribution analysis to estimate fluid forces around a foot during breaststroke kicking. Sports Eng. 2015; 18(3): 149-56. http://dx.doi.org/10.1007/s12283-015-0174-6

[13] Roriz P, Carvalho C, Frazão O, et al. From conventional sensors to fibre optic sensors for strain and force measurements in biomechanics applications: A review. J Biomech. 2014; 47(6): 1251-61. PMid:24612722. http://dx.doi.org/10.1016/j.jbiomech.2014.01.054

[14] Driscoll CO, Stanley W, Little EG. A comparison of three-dimensional embedded strain transducers, compression tested within the strain field while offset at an angle with the principal axes. Strain. 2012; 48(5): 375-87. http://dx.doi.org/10.1111/j.1475-1305.2012.00833.x

[15] Cavanagh PR, Palmgren JV, Kerr BA. A device to measure forces at the hands during the grab start. Proceedings of the International Series on Sport Sciences, Baltimore. 1975: 43-50p.

[16] Bracci JM, Reinhorn AM, Mander JB. Seismic Resistance of Reinforced Concrete Frame Structures Designed Only for Gravity Loads: Part I / Design and Properties of a One / Third Scale Model Structure. Technical Report NCEER-92-0027, National Center for Earthquake Engineering Research, SUNY/Buffalo, Geometric layout, strain gaging, and calibration charts of load cells. 1992.

[17] Galbraith H, Scurr J, Hencken C, et al. Biomechanical comparison of the track start and the modified one-handed track start in competitive swimming: an intervention study. J Appl Biomech. 2008; 24(4): 307-15. PMid:19075299.

[18] Esser SM, Vlietstra NJ, Farley DP, et al. An Extramedullary Three Degree of Freedom Limb Deformity Correction Device for Pediatric Applications. ASME Journal of Medical Devices. 2013: 1-26.

[19] Tor E, Pease DL, Ball KA. The reliability of an instrumented start block analysis system. J Appl Biomech. 2015; 31(1): 62-7. PMid:25268512. http://dx.doi.org/10.1123/JAB.2014-0155

[20] de Jesus K, Fernandes RJ, Vilas-Boas JP, et al. The backstroke swimming start: state of the art. J Human Kinet. 2014; 10(42): 27-40. http://dx.doi.org/10.2478/hukin-2014-0058

[21] Bobbert MF, Shamhardt HC. Accuracy of determining the point of force application with piezoelectric force plats. J Biomech. 1990; 23(7): 705-10. http://dx.doi.org/10.1016/0021-9290(90)90169-4

[22] Cunningham DM, Brown GW. Two devices for measuring the forces acting on the human body during walking. Proceeding of the Society for Experimental Stress Analyses; 1952. 75-90p. PMid:14892980. 